\title{
REGRESSÕES LINEARES EM GEOCRONOLOGIA: ISÓCRONAS, ERRÓCRONAS E PSEUDOISÓCRONAS
}

\author{
K.Kawashita ${ }^{1}$ \\ I.K.Sonoki ${ }^{1}$ \\ K.Sato ${ }^{1}$ \\ H.M.Sonoki ${ }^{1}$
}

Na maioria dos métodos geocronológicos, os dados experimentais são interpretados mediante a utilização dos diagramas conhecidos como isocrônicos. Nestes, as razões isotópicas (Yi) e razões ( $\mathrm{Xi}$ ) entre o radionuclídeo e um isótopo estável, que é comum às mesmas, de amostras cogenéticas ou supostamente cogenéticas, consangüíneas ou coevas, são lançadas em coordenadas (X, Y). Um dos métodos mais conhecidos e utilizados é o isocrônico $\mathrm{Rb} / \mathrm{Sr}$, preconizado por Nicolaysen (1961) em que as razões respectivas são ${ }^{87} \mathrm{Sr} /{ }^{86} \mathrm{Sr} \mathrm{e}{ }^{87} \mathrm{Rb} /{ }^{86} \mathrm{Sr}$. Quando há cogeneticidade e a variação das razões foi devida somente ao decaimento radioativo do ${ }^{87} \mathrm{Rb}$ (sistema fechado), os diagramas devem resultar em uma relação linear do tipo: $\mathrm{Y}=\mathbf{a}+\mathbf{b} * \mathrm{X}$ e os parâmetros desta melhor reta fornecerão a idade, dada pela inclinação b, e a razão dita inicial, dada pela interseç̧ão a. A questão se resume em escolher a técnica que calcule os melhores valores de a e b. Essa escolha depende primordialmente de 3 fatores: erros experimentais dos pontos, erros induzidos por processos geológicos (como sistema aberto ou onde ocorreram rehomogeneizações locais) e da natureza dos erros analíticos que são distintos conforme metodologia analítica e tipos de instrumentos utilizados.

Os principais tratamentos estatísticos estão abordados no trabalho de BROOKS et al. (1972) e são:

1 - Modelo York 1 e Williamson;

${ }^{1}$ Departamento de Geologia Geral, Instituto de Geociências/USP, São Paulo. 
2 - Modelos I, II, III e IV de McIntyre et al.;

3 - Modelo York 2;

4 - Modelo Wendt 1 e Wendt 2.

Além destes, relacionamos: regressões simples: $\mathrm{Y}$ em $\mathrm{X}$ ou $\mathrm{X}$ em $\mathrm{Y}$ ou média das duas técnicas (SHIELDS, 1963); Modelos de Cameron e outros (CAMERON et al., 1981) e Modelo de Vugrinovich (VUGRINOVICH, 1981).

A regressão simples é, certamente, a mais utilizada nos diversos ramos da ciência para se estimarem os parâmetros da melhor reta que se ajusta aos dados experimentais obtidos. Os parâmetros dessa melhor reta são obtidos pelo método usual dos mínimos quadrados e que consiste em minimizar os resíduos.

Nas regressões simples as coordenadas são assumidas como sendo sem erros, o que torna o método isocrônico inadequado, pois ambas as coordenadas são afetadas por erros, que variam de amostra para amostra e de laboratório para laboratório, conforme o tipo de análise e/ou instrumento utilizado.

Derek York e McIntyre, em 1966, foram os primeiros a adaptar o princípio dos mínimos quadrados para isócronas $\mathrm{Rb} / \mathrm{Sr}$, incorporando fatores de ponderacão Wi, levando em conta a estimativa dos erros individuais dos pontos. Os modelos posteriores, ressalvados os de CAMERON e outros (op.cit.) e o de VUGRINOVICH (op.cit.), são praticamente idênticos, exceto pela imposição do fator de correção r entre os erros de $\mathrm{Y}$ e X. Em caso de isócronas, conforme simulações efetuadas por BROOKS et al. (op.cit.) e em teste real efetuado por nós, os parâmetros resultantes sao praticamente iguais ou concordantes dentro dos erros obtidos para estes mesmos parâmetros.

Já no caso de errócronas, cujo critério principal para distinção com isócrona é a utilização do índice MSWD $=\left(\mathrm{W}_{\mathrm{i}}^{*}\left(\mathrm{Y}_{\mathrm{i}^{-}} \mathrm{a}^{-} \mathrm{b}^{*} \mathrm{X}_{\mathrm{i}}\right)^{2}\right) /(\mathrm{N}-2)$, os parâmetros e os erros associados resultantes podem ser drasticamente diferentes. Em um exemplo real, aplicados para 5 gnaisses migmatíticos coletados nas proximidades de Fortaleza de Minas, MG (dados inéditos do CPGeo) e adotando-se o formalismo usual para isócronas, obtiveram-se idades variando entre um mínimo de 1300 m.a. (regressão de Y em X) até o máximo de 2440 m.a. (York-2 para $r=1$ ) enquanto para as razões iniciais obtiveram-se 0,764 e 0,745, respectivamente.

Sob a denominação de pseudoisócronas, preferimos englobar todas as isócronas casuísticas ou acidentais fictícias artificiais e outras designações similares, cujas idades são destituídas de significado geológico. Entre tais isócronas, podemos englobar aquelas resultantes de misturas binárias de composições isotópicas distintas e em proporções variadas. 
Na utilização do método isocrônico, algumas observações importantes podem ser resumidas conforme se segue:

a - rochas comagmáticas que se mantiveram sempre fechadas isotopicamente têm seus pontos respectivos em diagrama isocrônico, teoricamente alinhados segundo uma reta, dentro dos limites dos erros experimentais de medida. Para se obterem as estimativas mais realísticas dos parâmetros, recomenda-se contudo que ao menos 3 amostras tenham razões $\mathrm{X}$ mais ou menos regularmente distribuídas entre os valores extremos. A concentração de pontos, especialmente próximos da origem, ou seja, com valores de $\mathrm{X}$ baixos devido à ponderação ser inversamente proporcional à variância, pode reforçar ou distorcer artificialmente a precisão do parâmetro a (razão inicial) em detrimento do parâmetro b. A inclinação é proporcional à idade, se bem que a mesma possa ser fictícia ou espúria.

b - quando não se verifica alinhamento, isto pode ser atribuído à causa de natureza geológica ou experimental, incluindo-se aqui eventual erro acidental verificado durante as diversas fases de preparação das amostras. Em tal caso é preciso buscar uma explicação do não alinhamento dos pontos e utilizar técnicas estatísticas adequadas.

c - no caso de estarmos face a uma isócrona, isto é, MSWD menor que o nível de corte, os parâmetros a e b podem ser calculados por qualquer um dos modelos estatísticos ponderados para erros experimentais. Conforme discutido, os parâmetros mais realísticos deverão ser obtidos segundo Williamson, e a seguir, Wendt 2, York 2 ou McIntyre I. Para o cálculos de erros, devem-se adotar modelos que sejam bastante sensíveis aos erros experimentais. Neste aspecto, qualquer um dos quatro modelos acima é, a nosso ver, perfeitamente adequado, sendo as estimativas dos erros bastante próximas entre si.

d - no caso de errócronas, em que os erros das medidas fogem totalmente dos conceitos estatísticos baseados em distribuição normal, vimos que os parâmetros e os erros respectivos obtidos usando os modelos estatísticos convencionais podem ser totalmente irrealísticos. A exceção fica por conta dos casos em que se utilizam apenas erros internos individuais de cada amostra que são sempre subestimados, podendo como conseqüência apresentar um MSWD alto, ou falsa indicação de errócrona. Ressalvado este último caso, deve prevalecer antes um bom senso crítico na interpretação da errócrona do que propriamente preocupação de saber o melhor formalismo estatístico. No entanto, dois aspectos salientes poderiam ser ressaltados: $1^{\varrho}$ - por razão exposta no início, os parâmetros a e b podem, conforme circunstâncias, indicar resultados não realísticos 
quando é aplicada a metodologia usual de ponderação dos pontos em função dos erros experimentais. Os modelos II, III e IV de McINTYRE et al. (1966) seriam as possíveis alternativas, conforme o caso. Nos casos não enquadrados em nenhum destes modelos ou quando não se conhece adequadamente a natureza e/ou precisão doo dos erros individuais, parece-nos mais recomendável utilizar as regressóes lineares simples. Neste caso, a inclinação b (idade) deve ser a média das 2 regressões lineares, enquanto que para o parâmetro a (razão inicial) deve ser aquele estimado a partir de regressão de Y em $\mathrm{X} ; 2$. - as estimativas dos erros, no caso de errócronas, não devem ser avaliadas segundo formulas convencionais conhecidas e os modelos II, III sugeridos por McIntyre seriam melhor aplicáveis.

\section{REFERÊNCIAS BIBLIOGRÁFICAS}

BROOKS, C.; HART, S.R.; WENDT, I. (1972) Realistic use of two-error regression treatments as applied to rubidium-strontium data. Reviews of Geophysics and Space Physics, 10(2):551-557.

CAMERON, M.; COLLERSON, K.D.; COMPSTON, W.; NORTON, R. (1981) The statistical analysis and interpretation of imperfectly fitted $\mathrm{Rb}-\mathrm{Sr}$ isochrons from polymetamorphic terrains. Geochimica et Cosmochimica Acta, 45:1078-1097.

NICOLAYSEN, L.O. (1961) Graphic interpretation of discordant age measurement of metamorphic rocks. Annals of the New York Academy of Sciences, 91(2):198-206.

SHIELDS, R.M. (1963) A computer program to calculate a least squares isochron and associated errors. M.I.T. Eleventh Annual Progress Report, p.149-152.

VUGRINOVICH, R.G. (1981) A distribution-free alternative to least-squares regression and its application to Rb-Sr isochron calculation. Mathematical Geology, 13(5):443-454 . 